\title{
Comparação entre dois meios de coleta e transporte para estudo da microbiota conjuntival de indivíduos normais
}

\author{
Comparison of two transportation media for study of normal individual \\ conjunctival microbiota
}

\author{
Daniel Cruz Nog'ueira1 \\ Suely Mitoi Ykko Ueda ${ }^{2}$ \\ Maria Aparecida Soares Murça ${ }^{3}$ \\ Wilson Takashi Hida ${ }^{4}$ \\ Sergio Felberg'5 \\ Leão Serruya ${ }^{6}$ \\ Richard Yudi Hida ${ }^{7}$
}

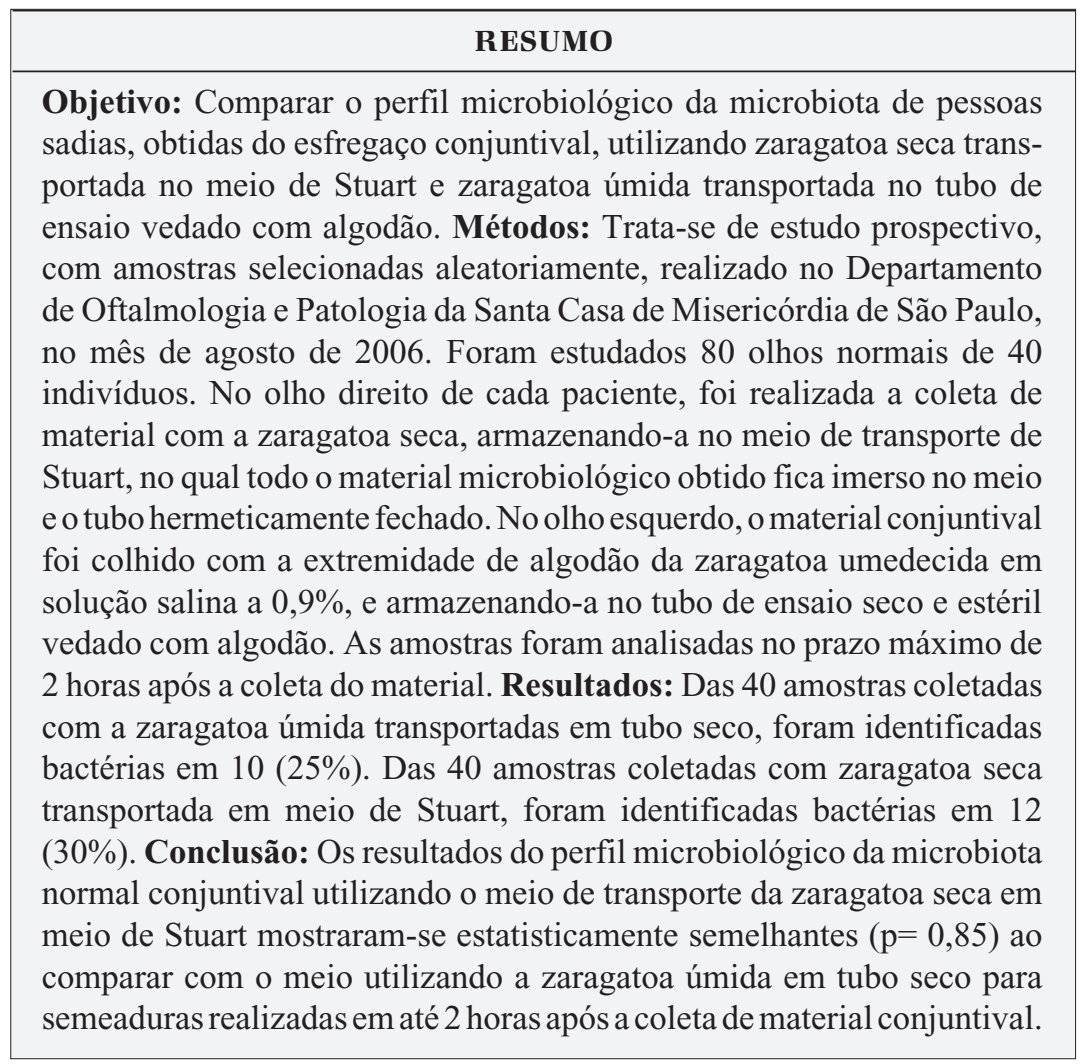

Descritores: Bactérias/isolamento \& purificação; Conjuntiva/microbiologia; Meios de cultura; Infecções oculares bacterianas

\section{INTRODUÇ̃̃O}

A flora bacteriana (ou microbiota) normal ocular da conjuntiva de indivíduos normais foi descrita por vários autores ${ }^{(1-3)}$ e é constituída por grande variedade de microrganismos em equilíbrio fisiológico entre seu próprio mecanismo patógeno (competição nutritiva, inibição metabólica e produção enzimática) e o sistema imunológico de seu hospedeiro ${ }^{(1)}$. Conseqüentemente, a conjuntiva, abriga uma rica microbiota comensal. Espécies geralmente encontradas na superfície ocular incluem Staphylococcus $\mathrm{sp}$, Streptococcus sp, Corynebacterium sp, diphtheroides e Moraxella $\mathrm{sp}^{(4-7)}$. A presença desta microbiota comensal, junto com a ação física das pálpe- 
bras e os efeitos químico e imunológico da lágrima, impedem a colonização de bactérias patogênicas. Não obstante, infecções de estruturas externas dos olhos não são raras, seja por resultado de microrganismos agressores ou por crescimento descontrolado das bactérias devido à quebra do equilíbrio imunológico do hospedeiro ${ }^{(5)}$.

O perfil da microbiota ocular sofre modificações constantes, influenciada por variações sazonais, temperatura, idade, fatores ambientais de exposição, traumatismo cirúrgico e imunidade do hospedeiro ${ }^{(1,4)}$. Para o estudo da microbiota conjuntival normal nos seres humanos, vários tipos de meios de cultura e técnicas microbiológicas são utilizados ${ }^{(6,8-9)}$. Dentre os meios de coleta, utilização da zaragatoa é muito comum, pela praticidade, baixo custo e facilidade de transporte, porém, a contaminação devida às inconveniências intrínsecas não é $\operatorname{rara}^{(8-9)}$. Para evitar contaminação e perda de material durante o processo de transporte, certas técnicas foram introduzidas e estudadas por outros autores ${ }^{(10-11)}$.

$\mathrm{O}$ meio de transporte de Stuart (Figura 1) consiste-se em ser semi-sólido, altamente redutor, isento de nutrientes, que inibe reações enzimáticas auto-destrutivas, especialmente a oxidação e pode provocar a morte bacteriana. É composto por cloreto de sódio, cloreto de potássio, fosfato dissódico, fosfato monopotássico, tioglicolato de sódio, cloreto de cálcio aquoso, cloreto de magnésio aquoso, ágar e água destilada. Seu $\mathrm{pH}$ é de $7,3^{(12)}$. É adequado para o transporte de Enterobacteriaceae, Haemophilus, Neisserias, Streptococcus, Bordetella, Staphylococcus, Pseudomonas, fungos e anaeróbios. Dependendo da espécie bacteriana, os microrganismos podem manter a viabilidade por mais de 72 horas a uma temperatura ambiente de 15 a $30^{\circ} \mathrm{C}^{(13)}$. O meio de Stuart é largamente utilizado em outras especialidades médicas, como gineco$\operatorname{logia}{ }^{(14)}$, otorrinolaringologia ${ }^{(15)}$ e infectologia ${ }^{(16)}$. Na oftalmologia, existem alguns estudos a esse respeito ${ }^{(10-11)}$.

Este estudo teve como objetivo comparar o perfil microbiológico proveniente de esfregaço conjuntival de indivíduos normais utilizando zaragatoa seca em meio de transporte de Stuart com a zaragatoa umedecida com solução salina estéril a $0,9 \%$ transportada em tubo seco estéril vedado com algodão.

\section{MÉTODOS}

Trata-se de estudo prospectivo, com amostras selecionadas aleatoriamente. Foi realizado no Departamento de Oftalmologia da Santa Casa de Misericórdia de São Paulo e na Disciplina de Microbiologia do Departamento de Patologia da Santa Casa Misericórdia de São Paulo, no mês de agosto de 2006 após aprovação do Comitê de Ética Médica da Santa Casa de São Paulo (protocolo de número 340/06). Todos os indivíduos que concordaram em participar desse estudo assinaram termo de consentimento após livre esclarecimento.

Foram analisados 80 olhos normais de 40 indivíduos com idade média de 29,85 $\pm 3,82$ anos (entre 25 e 39 anos), sendo
27 do sexo masculino e 13 do feminino. Foram incluídos no estudo, indivíduos que não apresentavam qualquer enfermidade ocular ou sistêmica, sem uso de medicação ocular ou lentes de contato nos últimos 30 dias, não ser procedente da zona rural e ter vontade de participar do estudo.

Os meios de transporte utilizados foram o de Stuart (Transprov III $^{\circledR}$, Newprov, Brasil) e o tubo de ensaio vedado com algodão (Laboratório de Microbiologia da Santa Casa de São Paulo, Brasil) (Figura 1 e Figura 2). Os esfregaços de conjuntiva foram coletados sempre na mesma sala, adotando cuidados como manter janelas fechadas para impedir a circulação de ar no ambiente. Todo o procedimento de coleta do material conjuntival foi realizado entre 8 horas e 13 horas, em ambiente fechado com temperatura ambiente que variou entre 16 e $24^{\circ} \mathrm{C}$.

\section{Técnica de coleta e transporte}

Para a coleta de material em ambos os olhos, foi instilada uma gota do anestésico lidocaína sem conservante a $2 \%$ (Lidocaína $2 \%{ }^{\circledR}$, Hipolabor, Brasil), com auxílio de uma seringa e cânula estéreis. Foi solicitado ao paciente que olhasse para cima, com o primeiro e o segundo dedos de uma das mãos seguravam-se as pálpebras, evertendo a inferior. Com a outra mão, aplicava-se a extremidade da zaragatoa com movimento de rotação e deslizamento sobre a superfície da conjuntiva palpebral e fundo de saco inferiores no sentido medial para lateral e lateral para medial, sem tocar nas margens palpebrais ou cílios.

No olho direito, foi realizada a coleta do material com a zaragatoa seca, armazenando-a no meio de transporte de Stuart (Figura 1), no qual todo o material microbiológico obtido fica imerso no meio e o tubo hermeticamente fechado. No olho esquerdo, o material conjuntival foi colhido usando a zaragatoa com sua extremidade de algodão umedecida com solução salina estéril a $0,9 \%$ (Aster ${ }^{\circledR}$, Brasil) e armazenando-a em tubo de ensaio estéril vedado com algodão (Figura 2). A manobra de coleta evitou o contato da zaragatoa com a margem palpebral, cílios ou margem do tubo. Em seguida, o material foi encaminhado ao Laboratório de Microbiologia, semeado em no máximo 2 horas após a coleta do material conjuntival.

Todo procedimento de coleta foi realizado pelo mesmo indivíduo, o autor do trabalho.

\section{Técnicas microbiológicas}

Todas as técnicas de semeadura, cultura, isolamento e antibiograma seguiram as normas e padronizações do Laboratório de Microbiologia do Departamento de Patologia da Santa Casa de São Paulo e do fabricante dos meios de transporte. Todo o processo microbiológico foi realizado pelo mesmo indivíduo, técnica do Laboratório de Microbiologia.

Os materiais foram semeados nas placas de cultura, ao lado de bico de Bunsen, na seqüência do meio menos seletivo para o mais seletivo: ágar sangue (Probac do Brasil ${ }^{\circledR}$, Brasil), 


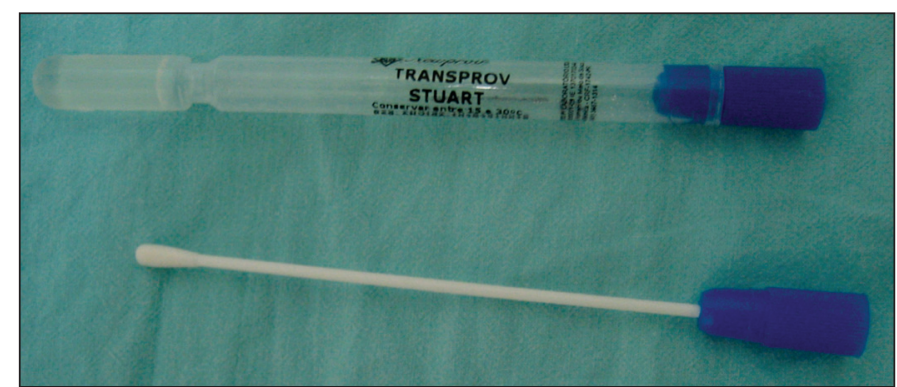

Figura 1 - Ilustração do meio de transporte de Stuart: Composto de zaragatoa e tubo fechado, contendo o meio de Stuart. Após a coleta do material biológico, a zaragatoa é introduzida no tubo com a extremidade de algodão imersa no meio de Stuart.

Fonte: Laboratório de Microbiologia do Serviço de Controle de Infecção Hospitalar do Departamento de Ciências Patológicas da Faculdade de Ciências Médicas da Santa Casa de São Paulo (Agosto 2006)

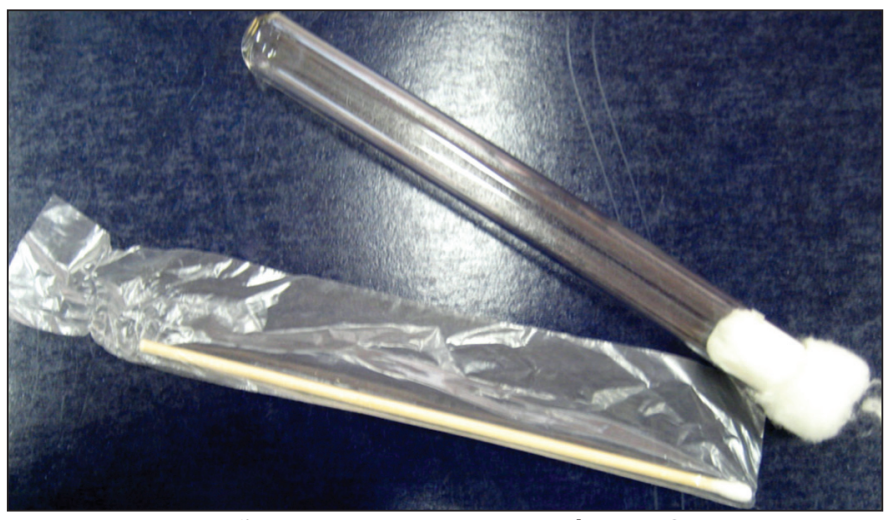

Figura 2 - Ilustração do meio da zaragatoa úmida: Composto de zaragatoa e tubo de ensaio vedado com algodão. Antes de coletar o material biológico, a extremidade de algodão é embebida por uma gota de solução fisiológica no momento da coleta. Após a coleta, a zaragatoa é colocada dentro do tubo de ensaio.

Fonte: Laboratório de Microbiologia do Serviço de Controle de Infecção Hospitalar do Departamento de Ciências Patológicas da Faculdade de Ciências Médicas da Santa Casa de São Paulo (Agosto 2006)

ágar chocolate (Probac do Brasil ${ }^{\circledR}$, Brasil) e ágar Sabouraud (Laboratório da Santa Casa/SP) respectivamente. Para a identificação de bactérias e fungos, os meios de cultura ágar sangue e ágar chocolate foram apresentados em placas de Petri de $60 \mathrm{~mm}$ e o ágar Sabouraud em tubo de ensaio. As placas foram semeadas de forma que todo o material da zaragatoa fosse transferido para a placa; para isso, a parte com ponta de algodão foi semeada por meio da técnica de rolamento e com auxílio de uma alça de platina, a semeadura foi realizada utilizando-se a técnica de esgotamento com o intuito de isolar as diferentes colônias de bactérias As placas de ágar sangue e ágar chocolate foram incubadas à temperatura de $35 \pm 2^{\circ} \mathrm{C}$; o ágar chocolate foi incubado em atmosfera de capnofilia, que favorece o crescimento de microrganismos fastidiosos, como alguns Streptococcus ssp, Haemophilus sp e Neisserias spp patogênicas. O ágar Sabouraud foi conservado em temperatura ambiente.

Foram realizadas as leituras diárias das placas, iniciandose 24 horas após a semeadura, até completar 48 horas para ágar sangue e ágar chocolate e 15 dias para ágar Sabouraud, seguindo a padronização do Laboratório de Microbiologia da Santa Casa de São Paulo. A análise foi considerada positiva quando houve crescimento bacteriano nos respectivos meios de cultura e este foi identificado. Os testes de susceptibilidade foram realizados por meio do método de difusão. O método de difusão ou Kirby-Bauer segue a padronização do inóculo pela comparação da turvação com a escala 0,5 de McFarland. Uma zaragatoa foi umedecida no meio nutriente TSB (tryptic soy broth) com o inóculo bacteriano isolado e semeada na placa de Müeller-Hinton (MH) em três posições, abrangendo toda a extensão da placa. Em seguida, foram colocados os discos, contendo uma concentração conhecida e padronizada do agente antimicrobiano, na placa de $\mathrm{MH}$ recém-inoculada. Então, imediatamente, foi iniciada a difusão e estabelecido o gradiente de concentração ao redor do disco de papel filtro. Após a incubação de 24 horas em temperatura de $35 \pm 2^{\circ} \mathrm{C}$, foi feita a leitura dos halos dos antimicrobianos, sendo a sensibilidade antimicrobiana classificada como resistente, sensível e intermediária, seguindo os critérios estabelecidos pelo CLSI (Clinical and Laboratory Standards Institute, 2006).

Os antimicrobianos testados seguiram a padronização do Laboratório de Microbiologia que segue as recomendações internacionais do CLSI e é adotada pelo Ministério da Saúde. Para microrganismos Gram-negativos, os antibióticos testados foram: cefepima, gentamicina, amicacina, cefotaxima, ceftriaxona, levofloxacina, cloranfenicol, tobramicina, ofloxacina, ciprofloxacino, gatifloxacina, imipenem, meropenem, aztreonan e sulfametoxazol-trimetoprim. Para os microrganismos Gram-positivos, os antibióticos testados foram: penicilina, oxacilina, eritromicina, vancomicina, cloranfenicol, ciprofloxacina, gatifloxacina, gentamicina, tetraciclina, cefepima, clindamicina, vancomicina, meropenem, teicoplamina, e sulfametoxazol-trimetoprim.

\section{Análise estatística}

Os dados foram tabulados em planilha eletrônica (Excel, Microsoft) e analisados estatisticamente com o teste de Fisher. Foi considerado, como nível de significância, $p<0,05$.

\section{RESULTADOS}

Das 40 amostras coletadas com zaragatoa úmida e transportadas no tubo estéril vedado com algodão, foi observada positividade em 10 (25\%). Das 40 amostras coletadas com zaragatoa seca e transportadas no meio de Stuart, foi observada positividade em $12(30 \%)$. Essas diferenças não se mostraram estatisticamente significantes $(\mathrm{p}=0,85)$ (Quadro 1).

Não foi observado crescimento de fungos em nenhuma das amostras estudadas.

No quadro 2 estão dispostos os microrganismos isolados, com seus respectivos antibiogramas nos dois meios de transporte. 
No resultado da análise do antibiograma dos microrganismos encontrados (Quadro 2), observamos que 6 pacientes (12 amostras) possuem o mesmo perfil bacteriológico em culturas provenientes de ambos os meios de transporte. Observamos também, que em 6 pacientes, houve crescimento bacteriano usando apenas o meio de transporte de Stuart, sendo negativas as amostras coletadas com a zaragatoa úmida. Em 4 pacientes, houve o crescimento bacteriano apenas nas amostras coletadas pela zaragatoa úmida.

\section{COMENTÁRIOS}

Alguns fatores variáveis podem influenciar nos estudos de coleta de microbiota conjuntival, tais como variações ambientais, variações nas técnicas de coleta (carga bacteriana coletada), fatores metabólicos do microrganismo (coletas em fase de morte celular do microrganismo), variações no perfil da microbiota entre os olhos do mesmo paciente, atividade antimicrobiana da lágrima e o tipo do anestésico tópico

\begin{tabular}{|c|c|c|c|c|c|c|}
\hline $\mathbf{N}$ & STUART & \multicolumn{2}{|c|}{ Microrganismo encontrado } & TE & \multicolumn{2}{|c|}{ Microrganismo encontrado } \\
\hline 1 & - & \multicolumn{2}{|c|}{-} & - & \multicolumn{2}{|c|}{-} \\
\hline 3 & + & Staphylococcus c & coagulase negativa & + & Staphylococcus & coagulase negativa \\
\hline 4 & + & Staphylococcus o & coagulase negativa & + & Staphylococcus & coagulase negativa \\
\hline 5 & - & \multicolumn{2}{|c|}{-} & + & Staphylococcus & coagulase negativa \\
\hline 8 & - & & - & - & \multicolumn{2}{|r|}{-} \\
\hline 9 & - & & - & - & \multicolumn{2}{|r|}{-} \\
\hline 10 & - & & - & - & \multicolumn{2}{|r|}{-} \\
\hline 11 & + & Staphylococcus aureu & eus/Corynebacterium ssp & - & \multicolumn{2}{|r|}{-} \\
\hline 12 & - & & - & - & \multicolumn{2}{|r|}{-} \\
\hline 17 & - & & - & - & \multicolumn{2}{|r|}{-} \\
\hline 18 & - & & - & - & \multicolumn{2}{|r|}{-} \\
\hline 19 & - & & - & - & \multicolumn{2}{|c|}{-} \\
\hline 20 & + & \multicolumn{2}{|c|}{ Pseudomonas aeruginosa } & + & \multicolumn{2}{|c|}{ Pseudomonas aeruginosa } \\
\hline 21 & - & \multicolumn{2}{|c|}{-} & - & \multicolumn{2}{|c|}{-} \\
\hline 22 & + & Staphylococcus & coagulase negativa & + & Staphylococcus & coagulase negativa \\
\hline 23 & + & Staphylococcus & coagulase negativa & - & & - \\
\hline 24 & + & Staphylococcus c & coagulase negativa & - & & - \\
\hline 25 & + & Staphyloco & occus aureus & - & & - \\
\hline 26 & + & Staphylococcus o & coagulase negativa & - & & - \\
\hline 27 & - & & - & + & Staphylococcus & coagulase negativa \\
\hline 36 & - & & - & - & & - \\
\hline 37 & - & & - & - & & - \\
\hline 38 & - & & - & - & & - \\
\hline 39 & + & Staphylococcus & coagulase negativa & + & Staphylococcus & coagulase negativa \\
\hline 40 & + & Staphylococcus & coagulase negativa & - & & - \\
\hline $\begin{array}{l}\mathrm{N}= \\
\text { cres } \\
\text { Fon } \\
\text { San }\end{array}$ & $\begin{array}{l}\text { a; STUART= } \\
\text { o bacteriano } \\
\text { oratório de N } \\
\text { a de São PaL }\end{array}$ & $\begin{array}{l}\text { atoa seca transportada con } \\
\text { lo; (-)= ausência de cresci } \\
\text { ologia do Serviço de Contro } \\
\text { osto 2006) }\end{array}$ & $\begin{array}{l}\text { om meio de Stuart; TE= zarag } \\
\text { cimento bacteriano } \\
\text { role de Infecção Hospitalar do }\end{array}$ & $\begin{array}{l}\text { sporta } \\
\text { de } \mathrm{Ci} \text { e }\end{array}$ & $\begin{array}{l}\text { de ensaio estéril ved } \\
\text { gicas da Faculdade }\end{array}$ & $\begin{array}{l}\text { dada com algodão; }(+)= \\
\text { de Ciências Médicas da }\end{array}$ \\
\hline
\end{tabular}




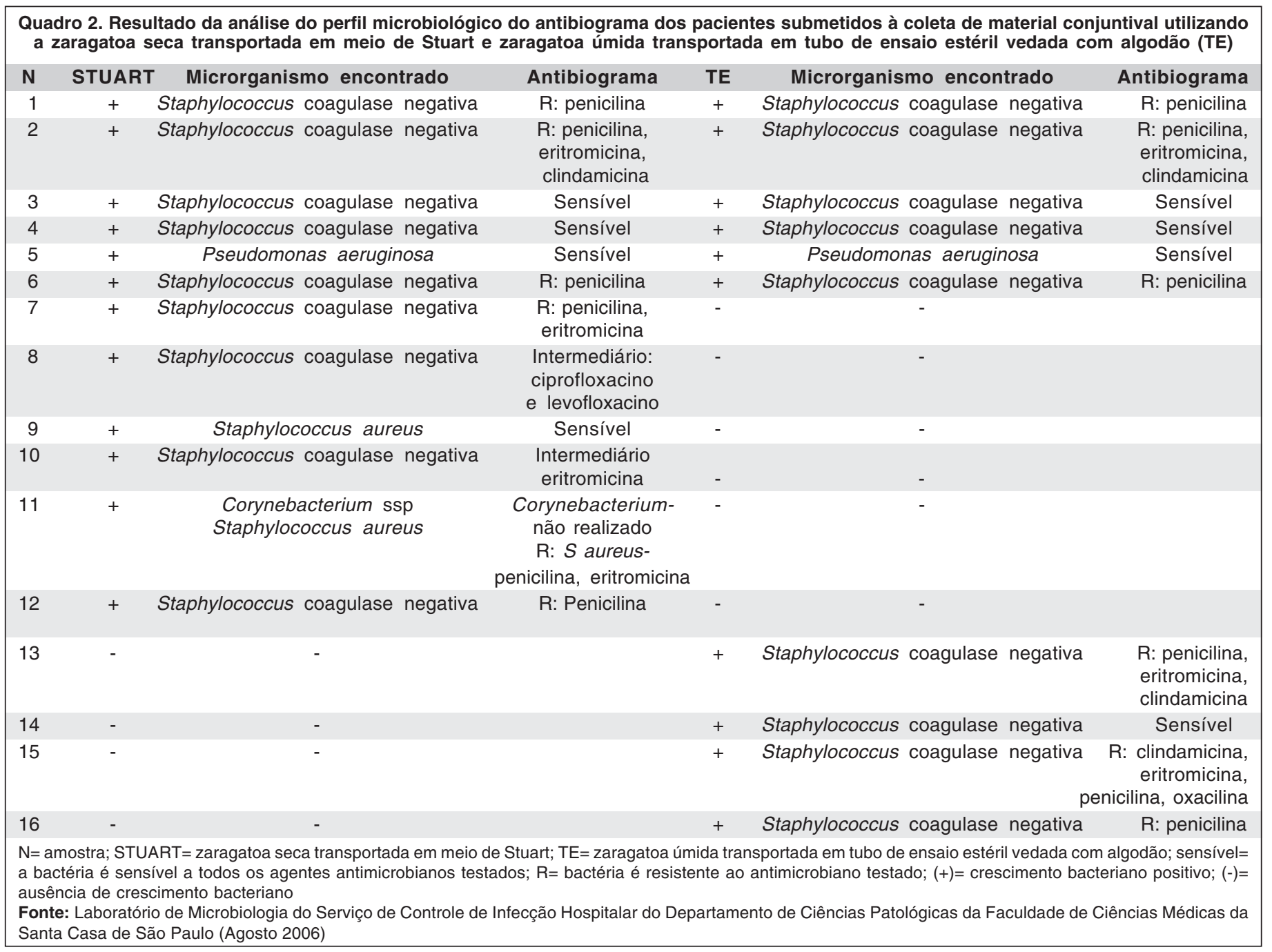

utilizado $^{(17)}$. Esses fatores podem justificar a diferença do resultado do perfil da cultura e antibiograma dos microrganismos encontrados entre amostras do esfregaço conjuntival dos olhos dos mesmos indivíduos, obtidos com técnicas distintas (Quadro 2). A variação da microbiota encontrada em sítios diferentes do olho de um mesmo indíviduo foi relatada por Nakata et al. que identificaram a diferença entre o perfil bacteriano de amostras colhidas da margem palpebral e do saco conjuntival de olhos de pessoas atópicas ${ }^{(18)}$.

O processamento e a cultura do material biológico proveniente de esfregaço conjuntival muitas vezes é realizada em laboratórios microbiológicos distantes do local de atendimento do paciente e da coleta do material biológico pelo oftalmologista. Isso resulta em intervalo muito variável entre o tempo entre a coleta e o processamento das amostras pelo laboratório. Para uma melhor sensibilidade e reprodutibilidade de realização de cultura da amostra colhida, o meio de transporte deve ser capaz de preservar o material o máximo de tempo após a coleta, mantendo a viabilidade do material até a sua semeadura ${ }^{(19)}$. Este estudo propôs comparar o meio de transporte de Stuart com métodos tradicionais usados na oftalmologia, pois o meio de Stuart possui um meio conservante, no qual os microrganismos têm maior chance de sobreviver até o processo de semeadura, cerca de 72 horas após a coleta $^{(13)}$

A preferência pelo uso da lidocaína $2 \%$, deve-se que em nosso trabalho piloto, todas as apresentações comerciais testadas (Anestalcon ${ }^{\circledR}$, Anestésico Allergan e Anestésico manufaturado pela Santa Casa-SP) apresentaram inibição do crescimento bacteriano em placas $\mathrm{MH}$ semeadas com cepas padronizadas pela CLSI. A quantidade de placas semeadas (4 por anestésico) é apenas suficiente para indícios, não para estatística.

Nos materiais biológicos conjuntivais coletados com a espátula de Kimura ou com a zaragatoa, a semeadura destes materiais obtidos deve ser em placas de cultura no momento da coleta do material, com gastos na obtenção destas placas. Utilizando os meios de transporte, o material coletado pode ser transportado ao laboratório e ser semeado por um microbiologista treinado, aumentando o tempo até a semeadura da 
amostra colhida. A zaragatoa úmida transportada em tubo de ensaio, exige que se realize a semeadura até 2 horas após a coleta do material conjuntival. A amostra, quando transportada em meio de Stuart, pode ser semeada em até 72 horas após a coleta do material conjuntival, apresentando vantagem deste meio em relação ao tubo de ensaio estéril. O aspecto relevante deste estudo, é que não houve estatisticamente diferença na positividade entre os dois meios de transporte para semeaduras realizadas até 2 horas após as coletas. Os meios de transporte estudados mostraram-se de fácil manuseio, versáteis e de custo acessível. Estes instrumentos microbiológicos podem ter boa aplicação na prática oftalmológica, principalmente em clínicas e hospitais que não dispõem de um laboratório de microbiologia. Porém, sugerimos novos estudos para analisar a reprodutibilidade e sensibilidade dos meios de transporte estudados em semeaduras realizadas no intervalo de tempo superior a 2 horas. A utilização da zaragatoa úmida transportada em tubo de ensaio estéril vedada com algodão, justifica-se por ser o meio de transporte mais utilizado na oftalmologia e em outras áreas médicas. E pode ser de grande importância quando a amostra é semeada em até 2 horas de sua coleta, devido ao seu baixo custo comparada com a zaragatoa seca transportada no meio de Stuart.

Sugerimos também novos estudos para analisar esses meios de transporte para amostras conjuntivais colhidas de olhos com infecção.

\section{CONCLUSÃO}

Os resultados do perfil microbiológico da coleta de material conjuntival de indivíduos normais utilizando a zaragatoa seca em meio de transporte de Stuart mostrou-se estatisticamente equivalente comparada à zaragatoa umedecida com solução salina estéril a $0,9 \%$ transportada em tubo seco estéril vedado com algodão em semeaduras realizadas em até 2 horas após a coleta de material conjuntival.

\section{ABSTR ACT}

Purpose: To compare the microbiological profile of normal microbiota of healthy people obtained from conjunctival smear using dry swab in Stuart's transport medium and wet swab transported in test tube sealed with cotton. Methods: A prospective study with random samples, performed at the Departments of Ophthalmology and Pathology of Santa Casa Misericórdia de São Paulo, in August of 2006. Eighty normal eyes of 40 healthy individuals were analyzed. Samples were collected in the right eye with a dry swab and stored in Stuart's medium, where all microbiological material is kept immersed in the medium and the tube is hermetically sealed. In the left eye, the conjunctival material was collected using a swab embedded in saline solution $0.9 \%$, and stored in dry and sterile test tubes sealed with cotton. The samples were analyzed within 2 hours at most after collection. Results: Out of 40 samples collected with wet swab and transported in dry tube, bacteria were observed in $10(25 \%)$, whereas of 40 samples collected with dry swab and transported in Stuart's medium, $12(30 \%)$ had bacteria. Conclusion: The results of the microbiological profile of normal conjunctival microbiota using dry swab in Stuart's medium were statistically similar $(\mathrm{p}=0.85)$ to those obtained in wet swab in dry tube for spreading performed within 2 hours after collection of conjunctival specimen.

Keywords: Bacteria/isolation \& purification; Conjunctiva/ microbiology; Culture media; Eye infections, bacterial

\section{REFERÊNCIAS}

1. Osato MS. Normal ocular flora. In: Pepose JS, Holland GN, Wilhelmus KR, editors. Ocular infection and immunity. St. Louis: Mosby; 1996. p.191-9.

2. Moeller CT, Branco BC, Yu MC, Farah ME, Santos MA, Höfling-Lima AL. Evaluation of normal ocular bacterial flora with two different culture media. Can J Ophthalmol. 2005;40(4):448-53.

3. Smolin G, Thoft RA, editors. The cornea: scientific foundations and clinical practice. $2^{\text {nd }}$ ed. Boston: Little, Brown; c1987. p.204-14.

4. Campos MS, Campos e Silva Lde Q, Rehder JR, Lee MB, O'Brien T, McDonnell PJ. Anaerobic flora of the conjunctival sac in patients with AIDS and with anophthalmia compared with normal eyes. Acta Ophthalmol (Copenh). 1994; $72(2): 241-5$.

5. Armstrong RA. Bug eyed. Microbiologist. 2003:26-9.

6. Liesegang TJ. Perioperative antibiotic prophylaxis in cataract surgery. Cornea. 1999;18(4):383-402. Erratum in: Cornea. 2000;19(1):123.

7. Locatcher-Chorazo D, Seegar BC. Microbiology of the eye: the bacterial flora of the healthy eye. St. Louis: Mosby; 1972. p.13-5.

8. O'Day DM, Akrabawi PL, Head WS, Ratner HB. Laboratory isolation techniques in human and experimental fungal infections. Am J Ophthalmol. 1979;87(5):688-93.

9. Barza M, Pavan PR, Doft BH, Wisniewski SR, Wilson LA, Han DP, Kelsey SF. Evaluation of microbiological diagnostic techniques in postoperative endophthalmitis in the Endophthalmitis Vitrectomy Study. Arch Ophthalmol. 1997; 115(9):1142-50

10. Reeder JC, Westwell AJ, Hutchinson DN. Indifferent streptococci in normal and purulent eyes of neonates. J Clin Pathol. 1985;38(8):942-5.

11. Arantes TEF, Cavalcanti RF, Diniz MFA, Severo MS, Lins Neto J, Castro CMMB. Conjunctival bacterial flora and antibiotic resistance pattern in patients undergoing cataract surgery. Arq Bras Oftalmol. 2006;69(1):33-6.

12. Koneman EW, Allen SD, Janda WM, Schreckenberger PC, Winn Jr SC. Diagnóstico microbiológico: texto e atlas colorido. $5^{\underline{a}}$ ed. Rio de Janeiro: Medsi; c2001.

13. PROBAC. Meio de transporte de Stuart. São Paulo: PROBAC do Brasil; 2006.

14. Donders GG, Vereecken A, Dekeersmaecker A, Van Bulck B, Spitz B. Wet mount microscopy reflects functional vaginal lactobacillary flora better than Gram stain. J Clin Pathol. 2000;53(4):308-13.

15. Gordts F, Abu Nasser I, Clement PA, Pierard D, Kaufman L. Bacteriology of the middle meatus in children. Int J Pediatr Otorhinolaryngol. 1999;48(2):163-7.

16. Togneri AM, Corso A, González J, Lopardo H, Podestá LB, Gagetti P, et al. [Clinical and epidemiologic analysis of intestinal tract colonization with vancomycin-resistant enterococci in an intensive care unit]. Rev Argent Microbiol. 2005;37(1):26-33. Spanish.

17. Hida RY, Ohashi Y, Takano Y, Dogru M, Goto E, Fujishima H, et al. Elevated levels of human alpha-defensin in tears of patients with allergic conjunctival disease complicated by corneal lesions: detection by SELDI ProteinChip system and quantification. Curr Eye Res. 2005;30(9):723-30.

18. Nakata K, Inoue Y, Harada J, Maeda N, Watanabe H, Tano Y, et al. A high incidence of Staphylococcus aureus colonization in the external eyes of patients with atopic dermatitis. Ophthalmology. 2000;107(12):2167-71.

19. Simões JA, Poletti GB, Portugal PM, Brolazo EM, Discacciati MG, Crema GD. Influência do conteúdo vaginal de gestantes sobre a recuperação do estreptococo do grupo B nos meios de transporte Stuart e Amies. Rev Bras Ginecol Obstet. 2005;27(11):672-6. 